\title{
Complete Mesocolic Excision With Central Vascular Ligation for the Treatment of Patients With Colon Cancer
}

\author{
Hyeong-Rok Kim \\ Division of Colorectal Surgery, Department of Surgery, Chonnam National University Medical School, Gwangju, Korea
}

\section{See Article on Page 180-186}

The colonic mesentery or mesocolon contains the vascular and the lymphatic drainage systems of the colon, so adequate clearance is necessary for colon cancer to have the same oncologic benefit as a total mesorectal excision for the treatment of patients with rectal cancer. In 2009, Hohenberger et al. [1] introduced a new concept trying to translate survival advantages to patients with colon cancer. This new concept of a complete mesocolic excision (CME) with a central vascular ligation (CVL) in the management of patients with colon cancer represents a kind of evolution in operative technique. The concept of a CME as a surgical technique with sharp dissection of the visceral plane from the retroperitoneal (parietal = somatic) one aims to avoid any breaching of the visceral fascia layer, which potentially may lead to tumor spread within the peritoneal cavity. With this procedure, the origin of the colonic arteries can be well exposed and tied centrally at their origins to ensure maximal harvesting of regional lymph nodes. CME and CVL surgery remove more tissue compared with standard surgery in terms of the distance between the tumor and the highly vascular region, the length of large bowel and ileum removed, and the area of the mesentery. In addition, CME and CVL surgery are associated with more mesocolic plane resections and greater lymph node yields $[2,3]$.

In terms of oncologic outcomes, Hohenberger et al. [1] reported excellent cancer-specific survival rates after CME surgery (stage I, 99.1\%; stage II, 91.4\%; and stage III, 70.2\%) [1]. Moreover, CME surgery is associated with better disease-free survival than is a

Correspondence to: Hyeong-Rok Kim, M.D.

Division of Colorectal Surgery, Department of Surgery, Chonnam National University Medical School, 160 Baeksuh-ro, Dong-gu, Gwangju 61469, Korea Tel: +82-61-379-7643, Fax: +82-61-379-7661

E-mail:drkhr@jnu.ac.kr

ORCID code: https://orcid.org/0000-0003-2737-0485

(C) 2018 The Korean Society of Coloproctology

This is an open-access article distributed under the terms of the Creative Commons Attribution NonCommercial License (http://creativecommons.org/licenses/by-nc/4.0) which permits unrestricted noncommercial use, distribution, and reproduction in any medium, provided the original work is properly cited. conventional colon cancer resection for patients with a stage I-III colon adenocarcinoma: the 4-year disease-free survivals were 85.8\% after CME and 75.9\% after non-CME surgery $(\mathrm{P}=0.0010)$. The 4-year disease-free survival for patients with Union for International Cancer Control (UICC) stage I disease in the CME group was $100 \%$ compared with $89.8 \%$ in the non-CME group (P $=0.046)$. For patients with UICC stage II disease, the 4 -year disease-free survival was $91.9 \%$ in the CME group compared with $77.9 \%$ in the non-CME group $(\mathrm{P}=0.0033)$, and for patients with UICC stage III disease, it was $73.5 \%$ in the CME group compared with $67.5 \%$ in the non-CME group $(\mathrm{P}=0.13)$. After propensity score matching, the disease-free survival was significantly higher after CME, irrespective of UICC stage, with 4-year disease-free survivals of $85.8 \%$ (95\% CI, 81.4-90.1) after CME and 73.4\% (95\% CI, 66.2-80.6) after non-CME $(\mathrm{P}=0.0014)$ [4].

The mean operative times ranged from 156 to 178 minutes [57], with the operative times for CME surgery being longer than those for non-CME surgery $[5,6]$. The postoperative morbidity rates ranged from $11 \%$ to $28 \%[1,5-7]$, but did not differ between the CME and the non-CME groups $[7,8]$. Similarly, no significant differences in outcomes between the CME (4.5\%) and the standard $(4.8 \%)$ colectomy groups regarding postoperative mortality were reported by 2 studies $[4,9]$. In particular, the rates of anastomotic leakage were also similar in 2 studies (CME surgery, $8.6 \%$ and $4.4 \%$; standard surgery, $7.6 \%$ and $5.2 \%)[4,5]$.

Applying laparoscopy to a CME for patients with colon cancer is difficult, mainly due to vascular dissection and splenic flexure mobilization [10]. Various laparoscopic and open techniques have been introduced in the literature for performing a CME with a CVL for patients with right-sided colon cancer. The laparoscopic approach is performed under the same CME principle as a laparotomy. Accordingly, skepticism exists as to whether the favorable outcomes of an open CME can be reproduced with a laparoscopic CME [11-14]. In a recent randomized trial, a laparoscopic D3 lymphadenectomy for patients with colon cancer showed shortterm surgical safety and clinical benefits when compared to the patients who had undergone open surgery. Yamamoto et al. [15] performed a randomized controlled trial comparing laparoscopic $(\mathrm{n}=533)$ and open D3 $(\mathrm{n}=524)$ dissections for patients with 
clinical stages II/III colon cancer. Conversion to open surgery occurred in 29 patients (5.4\%). The laparoscopic CME showed longer operative time (211 minutes vs. 153 minutes). However, shortterm advantages were observed in terms of less blood loss, shorter time to flatus, diminished analgesics use, shorter length of hospital stay, and lower postoperative complication rate $(14.3 \%$ vs. 22.3\%). When laparoscopic and open CMEs were compared, the overall survival rates (laparoscopy, $70.4 \%$ vs. open, $67 \%$ ) [16] and recurrence rates (laparoscopy, $8.6 \%$ vs. open, $9.1 \%$ ) were similar [17]. Cho et al. [18] reported similar overall and disease-free survival rates between the minimally invasive approaches (laparoscopy and robot) and an open CME. Bae et al. [19] reported a better overall survival rate in the laparoscopic $\mathrm{CME}$ group.

In conclusion, a CME with a CVL can be safely performed compared with non-CME surgery. CME surgery is associated with better disease-free survival than is conventional colon cancer resection for patients with a stages I-III colon adenocarcinoma. Thus, implementation of CME surgery might improve outcomes for patients with colon cancer. Although a laparoscopic CME is a technically demanding procedure and requires a steep learning curve due to technical difficulty, this approach may confer shortterm advantages, such as lower complication rates, shorter time to diet, and reduced hospital stay.

\section{CONFLICT OF INTEREST}

No potential conflict of interest relevant to this article was reported.

\section{REFERENCES}

1. Hohenberger W, Weber K, Matzel K, Papadopoulos T, Merkel S. Standardized surgery for colonic cancer: complete mesocolic excision and central ligation--technical notes and outcome. Colorectal Dis 2009;11:354-64.

2. West NP, Hohenberger W, Weber K, Perrakis A, Finan PJ, Quirke P. Complete mesocolic excision with central vascular ligation produces an oncologically superior specimen compared with standard surgery for carcinoma of the colon. J Clin Oncol 2010; 28:272-8.

3. Abdelkhalek M, Setit A, Bianco F, Belli A, Denewer A, Youssef TF, et al. Complete mesocolic excision with central vascular ligation in comparison with conventional surgery for patients with colon cancer - the experiences at two centers. Ann Coloproctol 2018;34:180-6.

4. Bertelsen CA, Neuenschwander AU, Jansen JE, Wilhelmsen M, Kirkegaard-Klitbo A, Tenma JR, et al. Disease-free survival after complete mesocolic excision compared with conventional colon cancer surgery: a retrospective, population-based study. Lancet Oncol 2015;16:161-8.

5. Galizia G, Lieto E, De Vita F, Ferraraccio F, Zamboli A, Mabilia A, et al. Is complete mesocolic excision with central vascular ligation safe and effective in the surgical treatment of right-sided colon cancers? A prospective study. Int J Colorectal Dis 2014;29:89-97.

6. Kanemitsu Y, Komori K, Kimura K, Kato T. D3 Lymph node dissection in right hemicolectomy with a no-touch isolation technique in patients with colon cancer. Dis Colon Rectum 2013;56: 815-24.

7. Tagliacozzo S, Tocchi A. Extended mesenteric excision in right hemicolectomy for carcinoma of the colon. Int J Colorectal Dis 1997;12:272-5.

8. Tentes AA, Mirelis C, Karanikiotis C, Korakianitis O. Radical lymph node resection of the retroperitoneal area for left-sided colon cancer. Langenbecks Arch Surg 2007;392:155-60.

9. Storli KE, Søndenaa K, Furnes B, Nesvik I, Gudlaugsson E, Bukholm I, et al. Short term results of complete (D3) vs. standard (D2) mesenteric excision in colon cancer shows improved outcome of complete mesenteric excision in patients with TNM stages I-II. Tech Coloproctol 2014;18:557-64.

10. Jamali FR, Soweid AM, Dimassi H, Bailey C, Leroy J, Marescaux J. Evaluating the degree of difficulty of laparoscopic colorectal surgery. Arch Surg 2008;143:762-7.

11. Melich G, Jeong DH, Hur H, Baik SH, Faria J, Kim NK, et al. Laparoscopic right hemicolectomy with complete mesocolic excision provides acceptable perioperative outcomes but is lengthy-analysis of learning curves for a novice minimally invasive surgeon. Can J Surg 2014;57:331-6.

12. Kang J, Kim IK, Kang SI, Sohn SK, Lee KY. Laparoscopic right hemicolectomy with complete mesocolic excision. Surg Endosc 2014;28:2747-51.

13. Adamina M, Manwaring ML, Park KJ, Delaney CP. Laparoscopic complete mesocolic excision for right colon cancer. Surg Endosc 2012;26:2976-80.

14. Willaert W, Ceelen W. Extent of surgery in cancer of the colon: is more better? World J Gastroenterol 2015;21:132-8.

15. Yamamoto S, Inomata M, Katayama H, Mizusawa J, Etoh T, Konishi F, et al. Short-term surgical outcomes from a randomized controlled trial to evaluate laparoscopic and open D3 dissection for stage II/III colon cancer: Japan Clinical Oncology Group Study JCOG 0404. Ann Surg 2014;260:23-30.

16. Han DP, Lu AG, Feng H, Wang PX, Cao QF, Zong YP, et al. Longterm outcome of laparoscopic-assisted right-hemicolectomy with D3 lymphadenectomy versus open surgery for colon carcinoma. Surg Today 2014;44:868-74.

17. Zhao LY, Liu H, Wang YN, Deng HJ, Xue Q, Li GX. Techniques and feasibility of laparoscopic extended right hemicolectomy with D3 lymphadenectomy. World J Gastroenterol 2014;20:10531-6.

18. Cho MS, Baek SJ, Hur H, Soh Min B, Baik SH, Kyu Kim N. Modified complete mesocolic excision with central vascular ligation for the treatment of right-sided colon cancer: long-term outcomes and prognostic factors. Ann Surg 2015;261:708-15.

19. Bae SU, Saklani AP, Lim DR, Kim DW, Hur H, Min BS, et al. Laparoscopic-assisted versus open complete mesocolic excision and central vascular ligation for right-sided colon cancer. Ann Surg Oncol 2014;21:2288-94. 